Supporting information

\title{
Rubrisandrins A and B, Lignans and Related Anti-HIV Compounds from Schisandra rubriflora
}

Min Chen, ${ }^{\dagger, \perp}$ Nicole Kilgore, ${ }^{\ddagger}$ Kuo-Hsiung Lee, ${ }^{\S^{*}}$ and Daofeng Chen ${ }^{\dagger *}$

* Corresponding author. Tel: +86-21-54237453. Fax: +86-21-64170921. E-mail: dfchen@ shmu.edu.cn (D.F.C.); or khlee@unc.edu (K. H. L.).

${ }^{\dagger}$ School of Pharmacy, Fudan University

${ }^{\ddagger}$ Panacos Pharmaceuticals, Inc.

${ }^{\S}$ Natural Products Research Laboratories, School of Pharmacy, University of North Carolina at Chapel Hill.

${ }^{\perp}$ Current address: School of Pharmacy, SouthWest University, Chongqing, 400715, People's Republic of China. 


\section{List of Legends}

S1. ${ }^{1} \mathrm{H}$ NMR (400MHz, $\mathrm{CDCl}_{3}$ ) of the new compound $1 \mathrm{a}$ and $1 \mathrm{~b}$

S2. ${ }^{1} \mathrm{C} \mathrm{NMR}\left(100 \mathrm{MHz}, \mathrm{CDCl}_{3}\right)$ of the new compound $1 \mathrm{a}$ and $1 \mathrm{~b}$

S3. HMQC of the new compound $1 \mathrm{a}$ and $1 \mathrm{~b}$

S4. HMBC of the new compound $1 \mathrm{a}$ and $1 \mathrm{~b}$

S5. NOESY of the new compound $1 \mathrm{a}$ and $1 \mathrm{~b}$

S6. ${ }^{1} \mathrm{H}$ NMR $\left(400 \mathrm{MHz}, \mathrm{CDCl}_{3}\right)$ of the new compound 2

S7. ${ }^{13} \mathrm{C} \mathrm{NMR}\left(100 \mathrm{MHz}, \mathrm{CDCl}_{3}\right)$ of the new compound 2

S8. ${ }^{1} \mathrm{H}-{ }^{1} \mathrm{H}$ COSY of the new compound 2

S9. NOESY of the new compound 2 


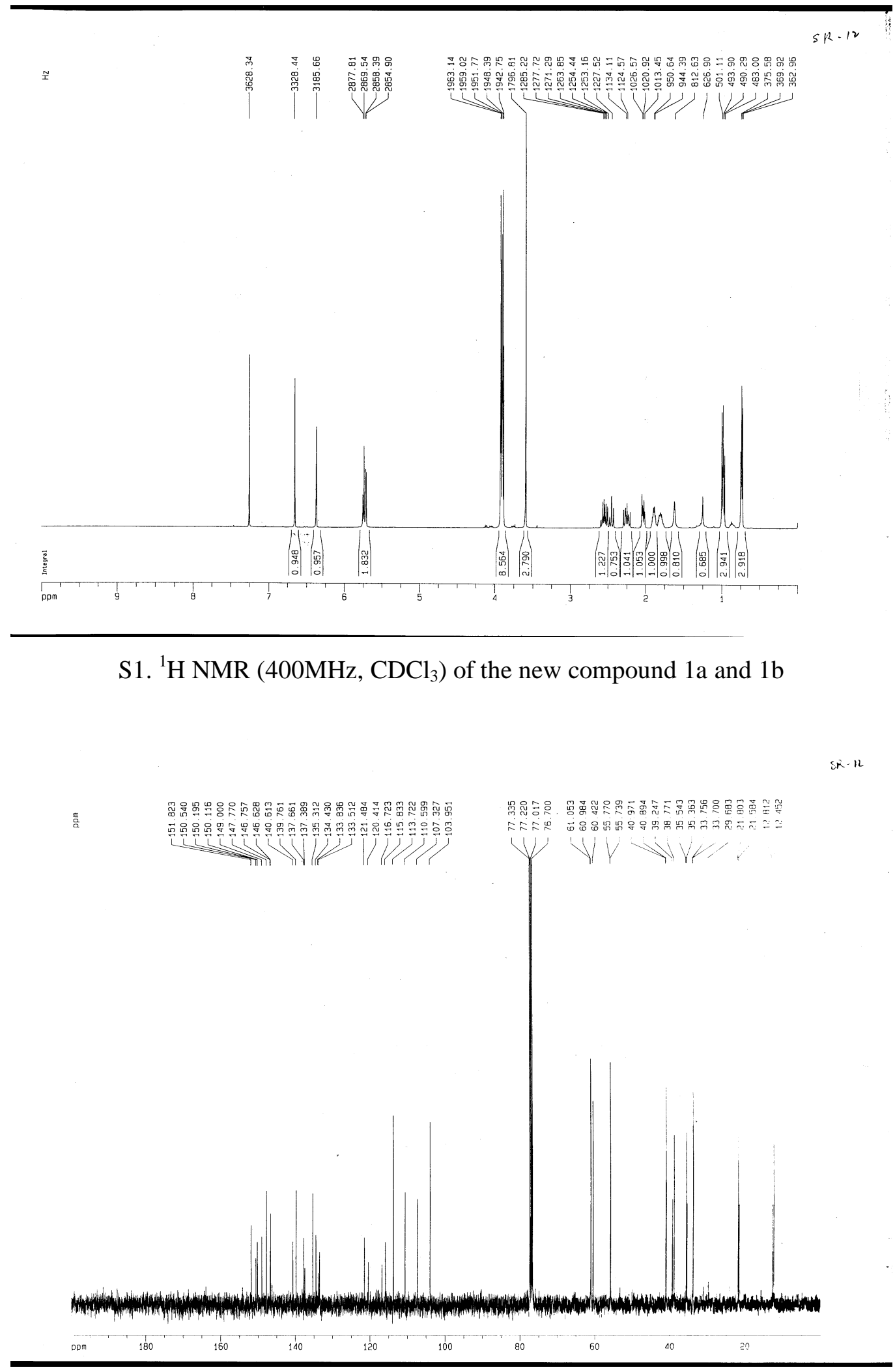

S2. ${ }^{1} \mathrm{C}$ NMR $\left(100 \mathrm{MHz}, \mathrm{CDCl}_{3}\right)$ of the new compound $1 \mathrm{a}$ and $1 \mathrm{~b}$ 


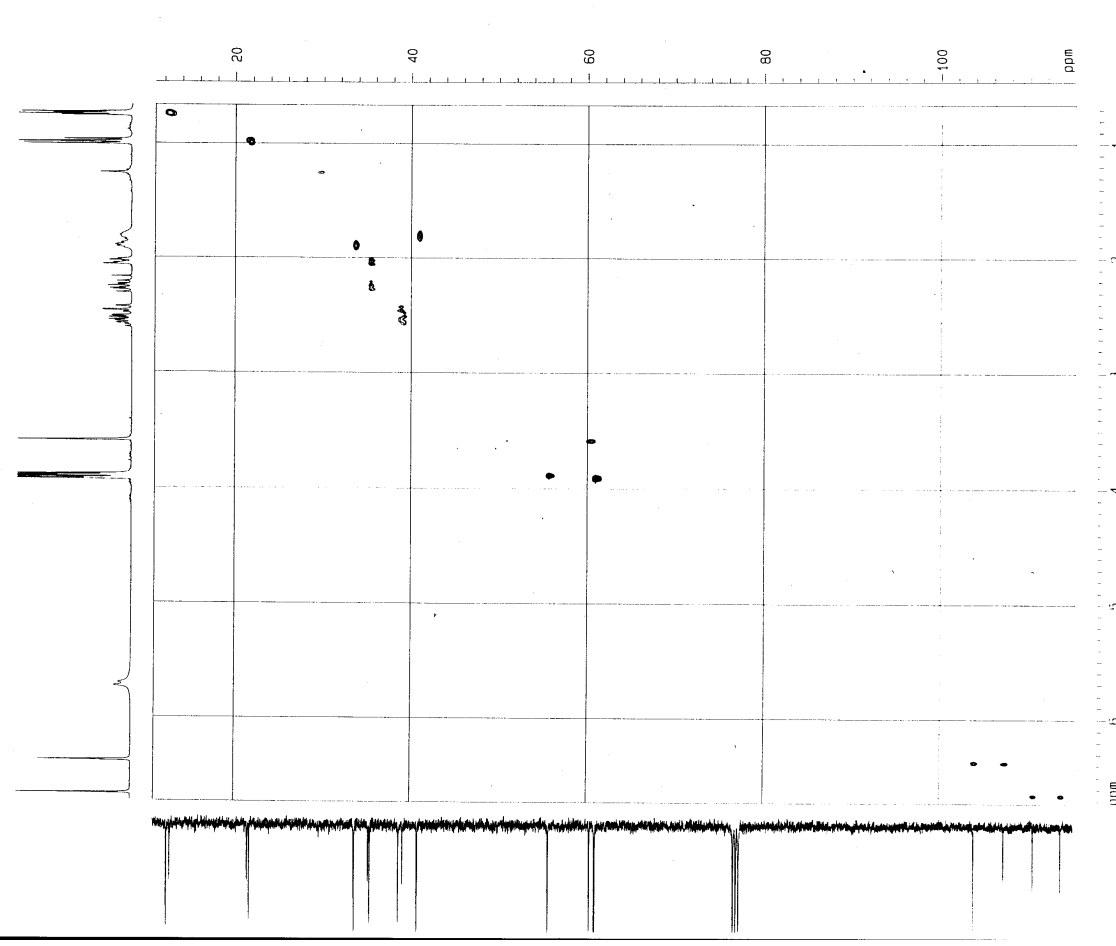

S3. HMQC of the new compound $1 \mathrm{a}$ and $1 \mathrm{~b}$

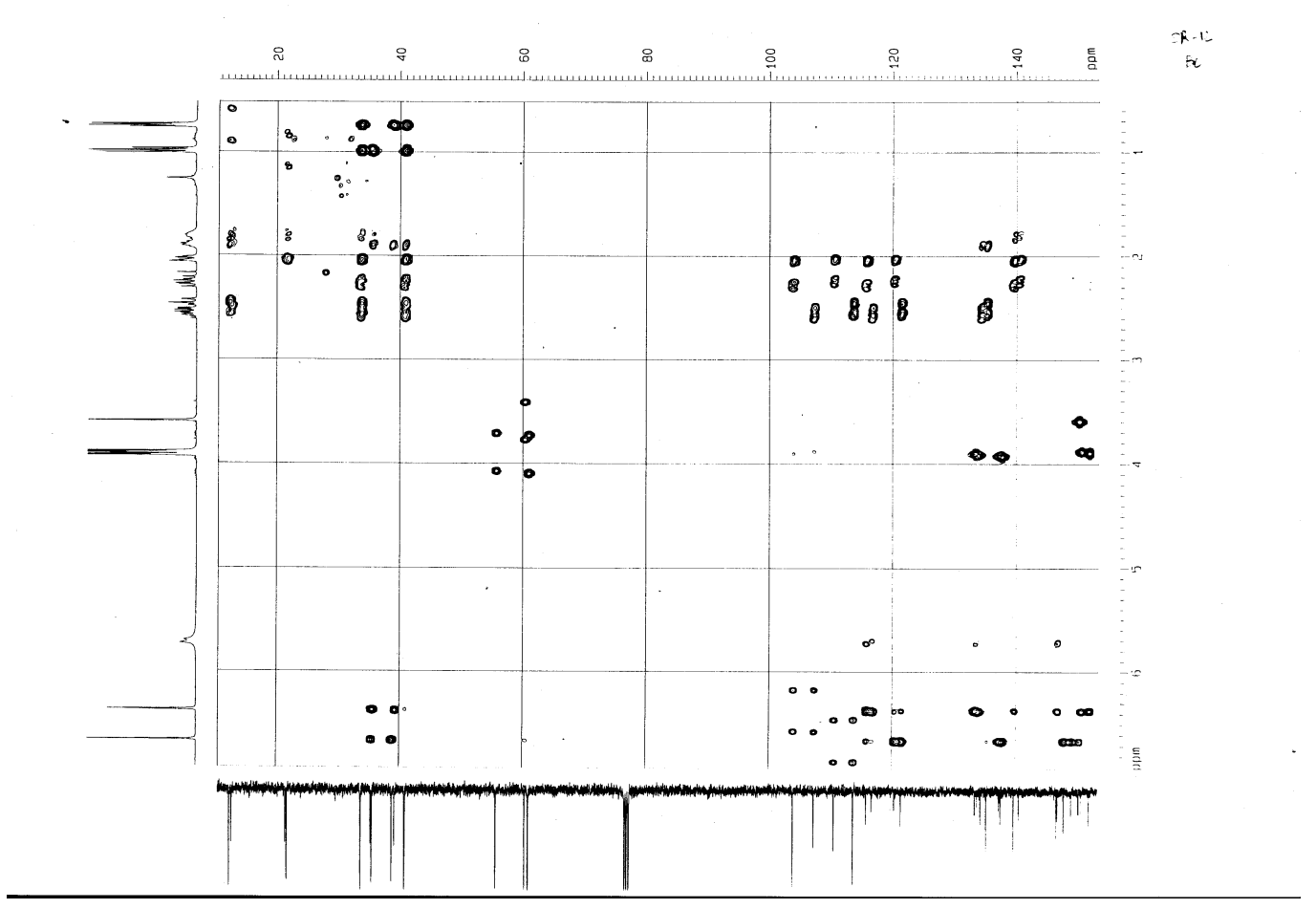

S4 HMBC of the new compound $1 \mathrm{a}$ and $1 \mathrm{~b}$ 

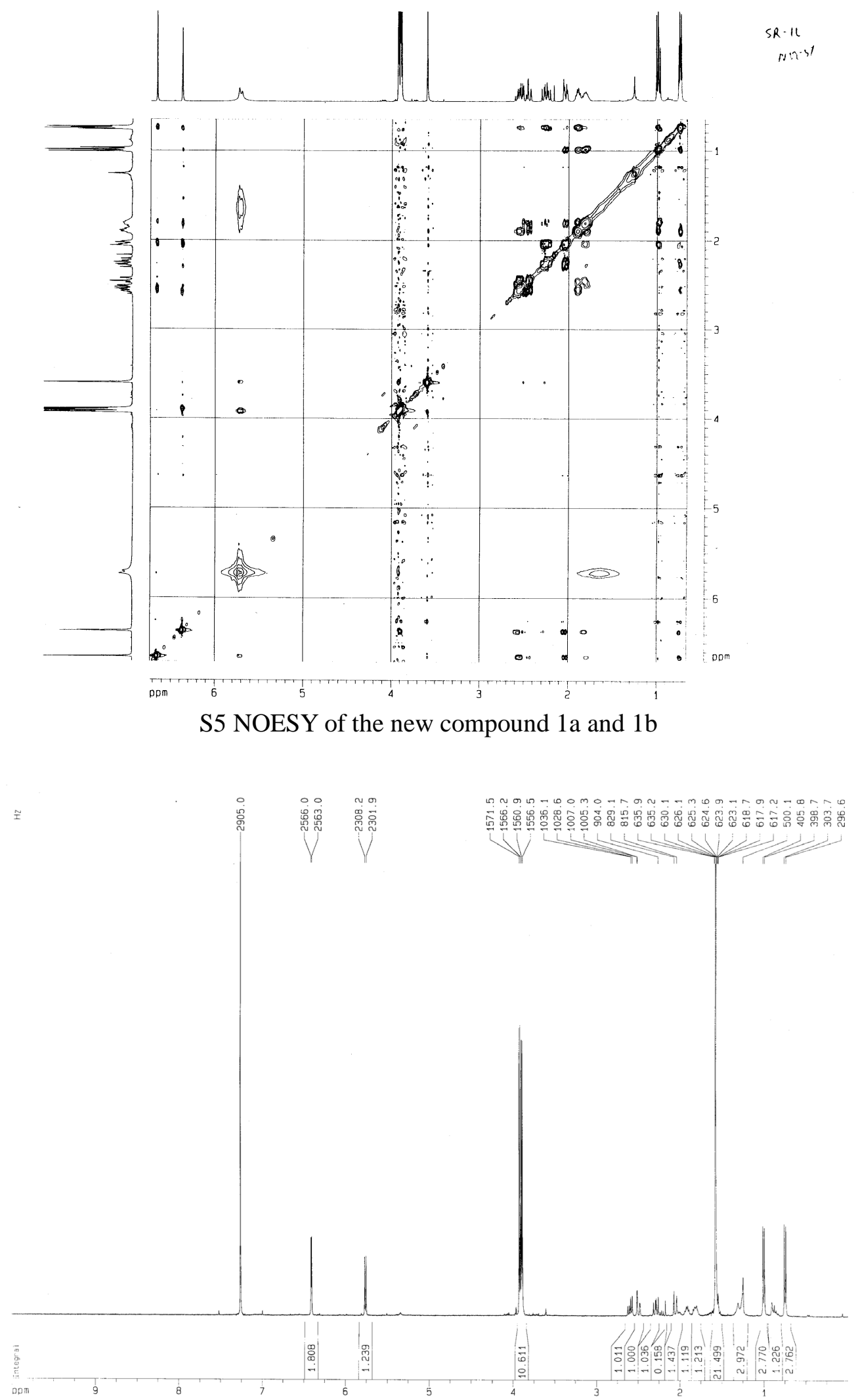

S6. ${ }^{1} \mathrm{H}$ NMR $\left(400 \mathrm{MHz}, \mathrm{CDCl}_{3}\right)$ of the new compound 2 


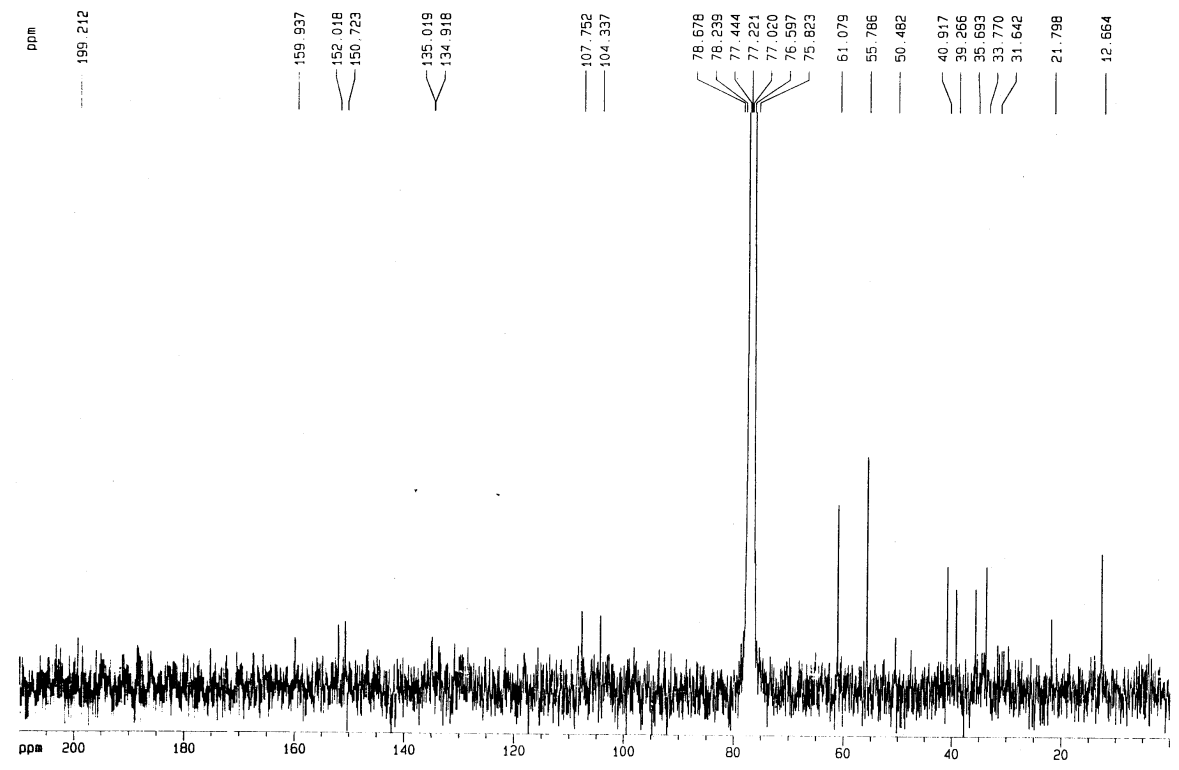

S7. ${ }^{13} \mathrm{C}$ NMR $\left(100 \mathrm{MHz}, \mathrm{CDCl}_{3}\right)$ of the new compound 2

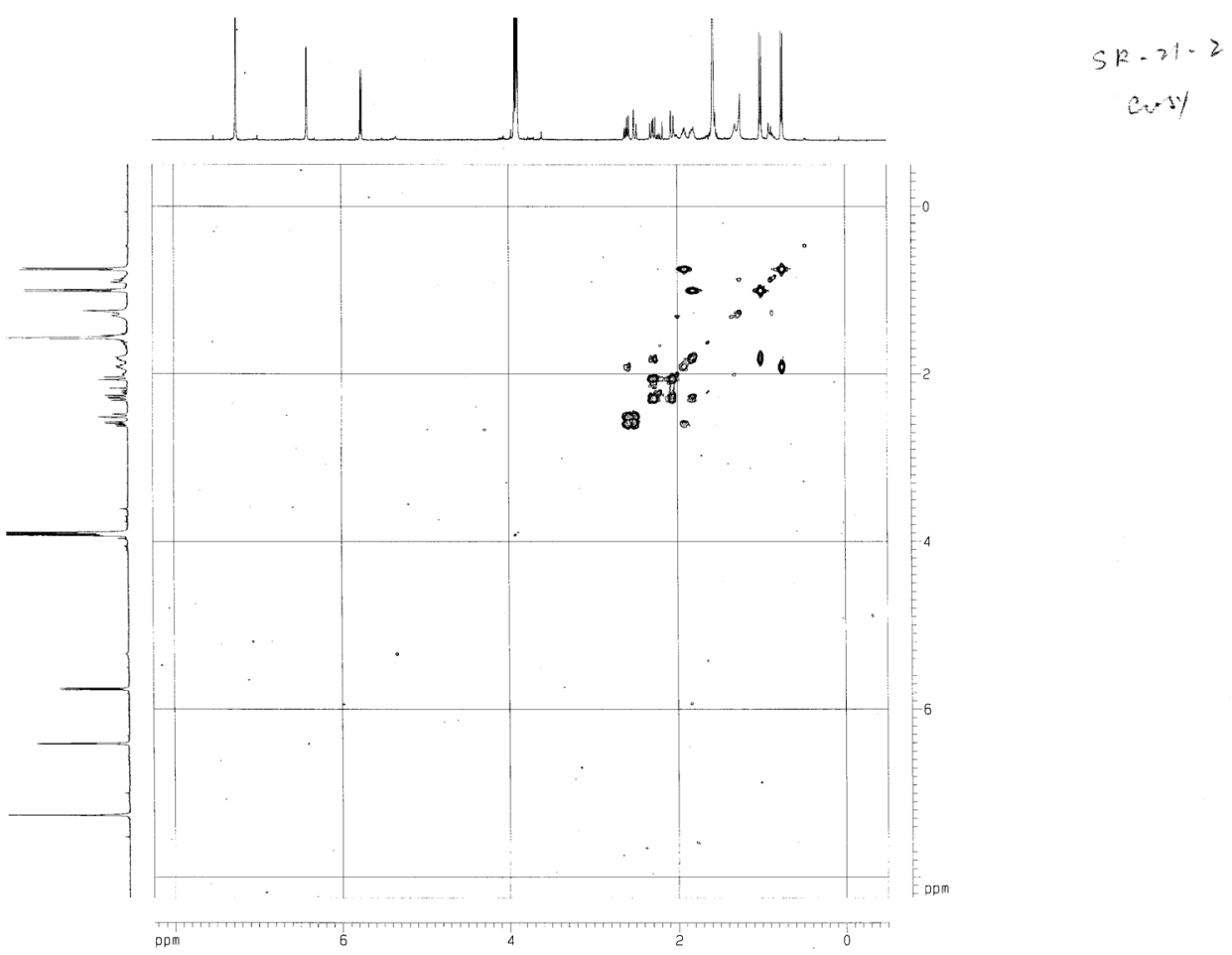

S8. ${ }^{1} \mathrm{H}-{ }^{1} \mathrm{H}$ COSY of the new compound 2 


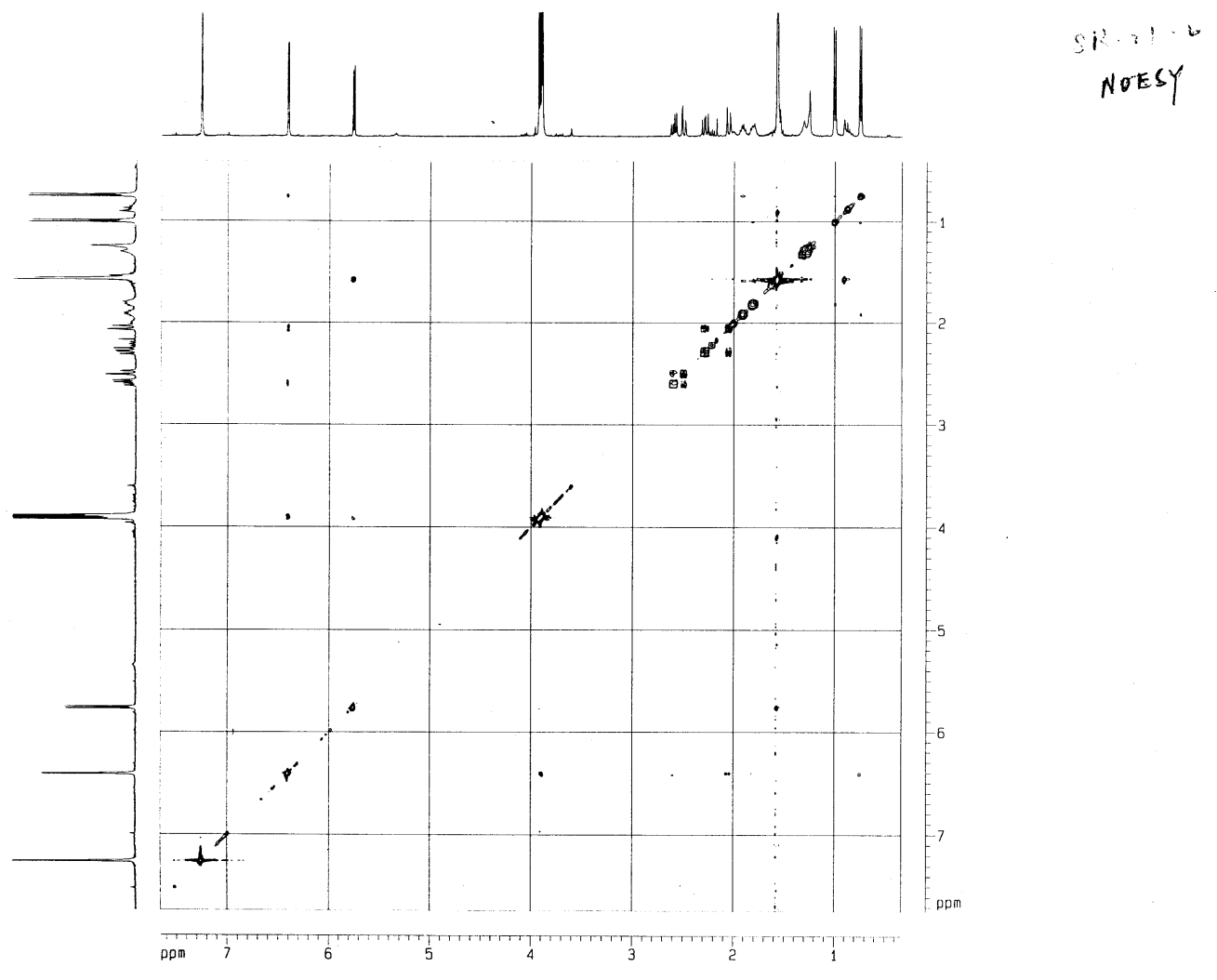

S9. NOESY of the new compound 2 